\title{
An experimental examination of the effectiveness of framing strategies to reduce mental health stigma
}

\author{
Bart Vyncke \\ KU Leuven, Institute for Media Studies \\ Parkstraat 45 - box 3603 \\ 3000 Leuven \\ Belgium \\ ORCID: 0000-0001-8276-0051
}

\author{
Baldwin Van Gorp \\ KU Leuven, Institute for Media Studies \\ Parkstraat 45 - box 3603 \\ 3000 Leuven \\ Belgium
}

\section{Acknowledgements}

This work was supported by Fonds Wetenschappelijk Onderzoek - Vlaanderen (FWO, ww.fwo.be/en/) under Grant FWO G070416N.

\section{Declarations of Interest}

The authors declare that there is no conflict of interest.

\section{Note}

This is the Author's Original Manuscript (i.e., preprint) of an article published by Taylor \& Francis in Journal of Health Communication on 29 October 2018. This version does not reflect any of the changes made during the peer-review process.

The final, published version of this article is available online: https://www.tandfonline.com/doi/full/10.1080/10810730.2018.1538272 


\title{
An experimental examination of the effectiveness of framing strategies to reduce mental health stigma
}

\begin{abstract}
The media are often blamed for perpetuating the stigma surrounding mental illnesses, but they can also be used to counter stigmatizing narratives. Drawing on framing theory, this study tested the potency of two framing strategies (deframing and reframing) to reduce mental health stigma, using an online between-subject posttest-only survey experiment $(N=$ 400), conducted in Belgium in November 2017.

For people without a personal history of mental illness, deframing (i.e., refuting the stigmatizing narrative) was able to significantly reduce public stigma, while reframing (i.e., introducing a new frame) lead to a significant reduction of perceived stigma. However, none of the framing strategies was able to significantly reduce public stigma, perceived stigma, or self-stigma held by people with a personal history of mental illness. Further, the frame's perceived persuasiveness was an important factor in determining framing effects, as unpersuasive frames increased support for the opposing position.

In summary, this study demonstrates that framing can serve as an important tool in creating anti-stigma messages. However, before disseminating such messages, it is important to keep into account the frame's persuasiveness, as well as how the same message may affect different target audiences.
\end{abstract}

Article keywords: Survey experiment; public stigma; self-stigma; mental illness; framing effects 


\section{Introduction}

Stigma occurs when "elements of labeling, stereotyping, separation, status loss, and discrimination co-occur in a power situation" (Link \& Phelan, 2001, p. 367). According to public opinion research, many people hold stigmatizing attitudes towards people with a mental illness (Crisp, Gelder, Rix, Meltzer, \& Rowlands, 2000; Reavley \& Jorm, 2011). This is called public stigma in stigma literature (Bos, Pryor, Reeder, \& Stutterheim, 2013). Public stigma complicates the lives of people suffering from mental illnesses, by posing substantial limits in areas such as housing, employment, and social contact (Clair, Daniel, \& Lamont, 2016; Link \& Phelan, 2001; Stuenkel \& Wong, 2009).

Stigma is formed in a process of socialization that teaches people what to expect from people with a mental illness, and how other members of society should treat them (Link \& Phelan, 2001; Link, Struening, Rahav, Phelan, \& Nuttbrock, 1997). Indirect experiences, such as media, play a role in shaping these expectations. It has been a common finding that the news media often depicts people with a mental illness in a stigmatizing way (e.g., Nawková et al., 2012; Rhydderch et al., 2016; Whitley \& Wang, 2017). This could lead to an increase of public stigma, but can also induce self-stigma, which refers to various psychological effects for people with a stigmatized condition (Bos et al., 2013; Boyd, Otilingam, \& DeForge, 2014). People who are mentally ill may expect or fear that members of society will stigmatize or discriminate them (i.e., perceived stigma; Bos et al., 2013; Link et al., 1997; Schomerus \& Angermeyer, 2008). Moreover, they may internalize negative stereotypes, leading them to believe they are less worthy (i.e., internalized stigma; Livingston \& Boyd, 2010; Stuenkel \& Wong, 2009). Self-stigma has been linked to a wide range of negative outcomes, such as reduced hope, self-esteem, quality of life, and treatment adherence (Boyd et al., 2014; Livingston \& Boyd, 2010). 
More empirical insight in how stigma can be reduced, is relevant from a scientific point of view, but can also be useful for organizations aiming to destigmatize mental illnesses. This study investigated how a written text can help reduce stigma through framing. It is one of the first to experimentally examine the effects of two strategies to counter an established frame: reframing and deframing (Feagin, 2010). Moreover, it pays attention to the framing effects on different forms of stigma. Especially perceived stigma and self-stigma have received relatively little research attention as of yet (Griffiths, Carron-Arthur, Parsons, \& Reid, 2014).

\section{Framing and stigma}

In light of a social constructionist approach to reality, the meaning of issues is not given. How issues are perceived, is not necessarily based on facts about an objective reality, but is instead a mental construction created in interaction with others (Van Gorp, 2007). Stigma is a clear example of a social construction, because a stigmatized attribute - such as having a mental illness - is only considered deviant because society has defined it as such (Major \& O'Brien, 2005; Stuenkel \& Wong, 2009). After all, attributes may be stigmatized in certain societies, social contexts, or timeframes, but can be considered normal in others (Bos et al., 2013; Clair et al., 2016; Link \& Phelan, 2001; Stuenkel \& Wong, 2009). As such, it should be feasible to destigmatize a condition.

Framing could be a helpful tool in the effort to redefine and destigmatize mental illnesses. A frame can be thought of as a perspective or narrative, that focuses on specific parts of the issue and ignores others (Entman, 2010; Van Gorp, 2007). By doing so, a frame simplifies and organizes information about the issue (Benford \& Snow, 2000). A frame promotes a certain way to look at the issue, by making the selected elements more salient (Entman, 2010). Additionally, framing will often introduce the audience to new 
considerations, making framing a form of persuasive communication (Chong \& Druckman, 2007b).

A large number of studies have shown that framing can influence the way the audience thinks about issues, including health and illnesses. For example, Wise and Brewer (2010) found that support for banning trans fats increased after participants had been exposed to a frame focusing on its negative effects on health. Framing effects can equally influence how one thinks about people suffering from a disease. In a study by Riles, Sangalang, Hurley, and Tewksbury (2015), the number of stigmatizing thoughts regarding people suffering from cancer was highest when cancer was framed as the consequence of lifestyle choices. When it was framed as being the result of genetic predisposition, however, the number of stigmatizing thoughts was significantly lower. These results provide tentative support for the hypothesis that frames can affect the stigma surrounding mental health issues as well.

Stigmatizing frames likely have an advantage over frames that aim to reduce stigma, because of two reasons. First, frames that appear repeatedly in the discourse gain persuasive strength and their effects become more durable (Chong \& Druckman, 2007a; Lecheler, Keer, Schuck, \& Hänggli, 2015; Van Gorp, 2007). Some evidence suggests that this is only the case for negative frames (Lecheler et al., 2015). As a result, stigmatizing frames are likely quite strong, as they are both negative and prevalent in news media from all across the globe (e.g., Nawková et al., 2012; Rhydderch et al., 2016; Whitley \& Wang, 2017).

Furthermore, frames that resonate with people's existing ideas, attitudes, and values are more resistant to change, while those that go against them are likely ineffective (Chong \& Druckman, 2007a, 2013; Entman, 2010). This is due to biased information processing: information that is supportive of a person's preexisting attitude is seen as more persuasive than contradicting information, and neutral information is seen as supportive of preexisting attitudes (Boysen \& Vogel, 2007; Druckman \& Bolsen, 2011). Since stigmatizing ideas are 
generally widely shared in society (Crisp et al., 2000; Reavley \& Jorm, 2011), it is likely that the stigmatizing frames will resonate with these attitudes. As such, they will likely be stronger than those trying to provide a destigmatizing alternative.

Although countering a stigmatizing frame will not be easy, Feagin (2010) suggested two possible strategies: deframing and reframing. Deframing refers to refuting elements of the original frame in order to undermine its narrative. For example, one could argue that people with a mental illness are generally not dangerous or unpredictable. However, this strategy could have negative consequences: Beukeboom, Finkenauer, and Wigboldus (2010) argue that using negations (e.g., "not violent") could backfire, by making the non-negated quality (e.g., "violent") more salient. Furthermore, these authors found that by using negations, a less positive image is created compared to the affirmation (e.g., "peaceful"). The negation also implies that it unlikely that the person will keep up the good behaviour in the future. This leads Beukeboom et al. (2010) to hypothesize that negations will uphold stereotypes.

Reframing is the second strategy to counter a frame (Feagin, 2010). In reframing, one introduces a new frame, offering the public a novel way of looking at the issue without referencing the original frame. Offering alternative viewpoints likely encourages the audience to critically examine the frames (Chong \& Druckman, 2007a, 2013; Druckman \& Bolsen, 2011). As such, reframing could facilitate reasonable opinion formation (Druckman \& Bolsen, 2011, p. 681). However, in order to be effective, the new frames should be credible and interact with one's ideology and understanding of the issue (Clair et al., 2016). If not, Chong and Druckman (2007a) predict that the new frame will not be able to counteract the effects of the original frame, and may even increase those effects.

RQ1: Which counterframing strategy - reframing or deframing - is the most effective in reducing public stigma and perceived stigma surrounding mental illness? 
RQ2: Which counterframing strategy is the most effective in reducing the self-stigma of people with a personal history of mental illnesses?

\section{Methodology}

\section{Stimulus and procedure}

The Social and Societal Ethics Committee of KU Leuven granted approval for this research (SMEC G-2015 12 415). An online between-subject posttest-only survey experiment was conducted in Belgium in November 2017. It had four conditions, to which participants were randomly assigned. All participants received the same short overview of the issue (see Appendix I). Participants in the control group were not presented with any additional text, while those in one of the three experimental conditions were exposed to short, constructed opinion pieces, which discussed the difficulties that people with a mental illness experience in obtaining various kinds of insurance (see Appendix I). The stimuli were said to have been published in Knack, a Belgian weekly news magazine. They were attributed to the same source (a fictional health economist) and were similar in length, with word counts ranging from 319 to 326 .

To ensure the frames' ecological validity, they were taken from a framing analysis that investigated how the Belgian media represented mental illnesses (Van Gorp, Vyncke, Vergauwen, Smits, Vercruysse, \& Vroonen, 2017). In the frame condition, participants read a text that used a stigmatizing frame, The weakest link. This frame implicitly defines mental illnesses as being caused by having a weak character. To evoke this problem definition, the text argued that people with a mental illness have a higher risk of self-destructive behavior, are generally being unable to hold a job, and abuse the system by making others pay for their psychological help. 
In the deframing condition, these stigmatizing notion were dispelled. For example, the text argued that people with a mental illness "are certainly not written off", and that "it is wrong to assume that they have a permanent higher risk to get addicted or to commit suicide".

The reframing text used the counterframe A mosaic (Van Gorp et al., 2017), which defined a mental illness as being only a small part of the person as a whole. As a result, the frame argued that one should look beyond the arbitrary labels to see the person as a whole. Clair et al. (2016) argued that the strategy of drawing equivalences between the stigmatized and those who stigmatize has been effective in reducing stigma.

\section{Participants}

The participants were recruited from the panel of iVox, a Belgian market research and polling agency. For this study, participants had to live in Belgium, speak Dutch, and be 18 years or older. To have sufficient statistical power for the analyses, the quota was set at 100 participants per condition, or 400 participants in total. To ensure that participants read the questions thoroughly, an attention-check was incorporated. Participants who failed this attention-check did not add to the quota, and were deleted from the final sample.

After weighing, the sample was representative for the Belgian population regarding gender, social class, and age (in three categories: under 34 years old, between 34 and 54 years old, and older than 55 years old). All reported results make use of the weighed sample.

\section{Measures}

After obtaining informed consent, participants were asked to indicate their gender and age. Next, an adapted version of a seven-item scale by Corrigan, Markowitz, Watson, Rowan, and Kubiak (2003) was used to measure the amount of contact participants have had with people with mental illness (e.g., "A friend of the family has a mental illness"). Additionally, participants were asked to indicate whether they have a mental illness, or had one in the past. 
To determinate the persuasive strength of the frames, participants rated the argument on six criteria, using 5-point Likert scales. Specifically, they rated the argument's believability, persuasiveness, and their agreement with it, as well as to what extent the topic was relevant to their own lives, whether the author's opinion corresponded to their own, and whether they thought - based on their own experiences and knowledge - that the text offered a correct representation of the issue. Further, they gave their opinion about the message's source. Using 5-point Likert-scales, they indicated whether they thought that the source had relevant knowledge, as well as whether it could be trusted to not withhold information (Druckman, 2001). A Principal Component Analysis using Varimax rotation was conducted on the items measuring texts dimensions and source reliability. It revealed a single factor, which explained $55.98 \%$ of the variance and had good reliability (Cronbach's $\alpha=.89$ ). This factor was labeled as the frame's strength.

Next, participants were asked to make a policy choice. They had the choice to either allow insurance companies to continue using mental illness as a criterion for making decisions about granting insurance policies, or to forbid this practice.

Three different forms of stigma served as the dependent variables: public stigma, perceived stigma, and internalized stigma. Public and perceived stigma were measured with two 9-items Likert-scales, developed by Griffiths, Christensen, Jorm, Evans, and Groves (2004). The public stigma scale asks participants to indicate their agreement with stigmatizing statements (e.g., "Mental illnesses are a sign of personal weakness"). The perceived stigma scale consists of the same questions, except it asks the participant to rate how most people would feel (e.g., "Most people think that mental illnesses are a sign of personal weakness"). Both the factor for public stigma (Cronbach's $\alpha=.74$ ) and perceived stigma (Cronbach's $\alpha=.76$ ) had good internal consistency. 
Participants who had indicated that they had personally suffered from a mental illness were asked to fill in an adapted version of the Rejection Experiences Scale (Link et al., 1997; e.g., "Have people treated you unfairly because they knew you have or had a mental illness?"), as well as the 10-item version of Internalized Stigma of Mental Illness Scale (ISMI-10) (Boyd et al., 2014). Both the Rejection Experiences Scale (Cronbach's $\alpha=.83$ ) and the ISMI-10 (Cronbach's $\alpha=.76$ ) had a good internal consistency in this study.

Since social desirability bias was a cause for concern, stigma was also measured by a 9-point semantic differential that asked respondents whether they thought that "people with mental illness" are similar or different from them. Corrigan, Bink, Fokuo, and Schmidt (2015) argued that these semantic differentials are less affected by socially desirable responding than traditional Likert-scales.

The questionnaire also contained a 3-item Likert scale of personal responsibility beliefs, adapted from Corrigan et al. (2003). Although the reliability was somewhat lower than in the original study, it remained acceptable (Cronbach's $\alpha=.66$ ).

All scales were translated in Dutch by the research team. Several measures were taken to prevent order effects. First, the order of the items in most scales was randomized. Second, the scales regarding public stigma, perceived stigma, personal responsibility beliefs, and the similar-different semantic were presented in a random order. However, due to a programming oversight, the personal responsibility beliefs were always followed by the similar-different semantic differential. Questions regarding internalized stigma and discrimination were always asked at the end of the survey, but their order was randomized as well.

\section{Results}

Table 1 gives an overview of the socio-demographic variables of the sample, as well as the descriptive statistics for the variables used in the regression analyses.

[[TABLE 1 ABOUT HERE]] 
Hierarchical regression analyses were used to answer the research questions. In each model, all variables were entered simultaneously. In the models including interaction terms, diagnostics indicated that there was some cause for concern regarding multicollinearity between personal experience with mental illness, the framing strategies, and their interaction terms, as the VIFs ranged from 1.81 to 5.09. Brambor, Clark, and Golder (2005) argued that increased multicollinearity is not problematic when including multiplicative interactions, and that one should neither omit the constitutive terms nor center the variables in response. As such, no actions were taken to reduce multicollinearity.

\section{Blame}

A linear regression analysis was conducted to investigate whether framing could influence the amount of blame one attaches to people with mental health issues, $R^{2}=.04$, $F(8,391)=2.05, p=.040$. When controlling for gender, age, SES, previous contact with people with a mental illness, and having a personal history of mental illness, the experimental manipulations did not significantly influence blame. Only the amount of previous contact was a significant predictor, $b=-0.13,95 \%$ CI $[-0.21,-0.04], \beta=-0.16, p=.004$. Adding the interaction terms caused the model to lose its significance, $R^{2}=.04, F(11,388)=1.66, p$ $=.082$.

\section{Public stigma}

The first model for public stigma indicated that responsibility beliefs was the most powerful predictor. More blame was associated with higher public stigma (see Table 2). Turning to the experimental conditions, both deframing (i.e., refuting the stigmatizing frame) and reframing (i.e., introducing a new frame) were significantly associated with lower public stigma, compared to the control. When introducing the interaction terms, reframing loses its significance as a predictor $(p=0.069)$. Remarkably, in this second model, participants without personal experience had significantly lower public stigma when being exposed to the 
stigmatizing frame. This was not the case for people with a personal history of mental illness, as indicated by the significant interaction effect. When they had been exposed to the stigmatizing frame, they had higher public stigma $(M=2.43, S D=0.37)$ than in the controlcondition $(M=2.14, S D=0.30)$.

\section{[[TABLE 2 ABOUT HERE]]}

Chong and Druckman (2007a) argued that unpersuasive frames could inadvertently increase support for the opposite argument. A one-way Anova showed that the stigmatizing frame condition was indeed deemed significantly less persuasive $(M=-0.60, S D=0.91)$ than the deframe condition $(M=0.33, S D=0.81)$ and the reframe condition $(M=0.28, S D=0.98)$, $F(2,301)=34.43, p<.001$.

To investigate whether the decrease in public stigma associated with exposure to the stigmatizing frame was due to a backfire-effect, independent t-tests compared public stigma between participants who found the argument to be persuasive, and those who did not (see Table 3). Results supported the hypothesis of a backfire-effect: when the stigmatizing frame was deemed unpersuasive (factor score < 0), public stigma was significantly lower than when it was deemed persuasive (factor score $\geq 0$ ). The opposite was true for the stigma-reducing strategies.

\section{[[TABLE 3 ABOUT HERE]]}

\section{Perceived similarity with people with a mental illness}

Perceived similarity with people with a mental illness was only significantly predicted by having a personal experience with mental illness and one's responsibility beliefs in the first model (see Table 4). After adding the interaction terms, personal experience with a mental illness ceased to be a predictor, although it still approached significance $(p=.050)$. Further, one interaction term was significant: people with a personal experience who were 
exposed to the frame identified less with the group of "people with a mental illness" $(M=$ 4.75, $S D=1.75)$ compared to people in the control condition $(M=6.59, S D=2.24)$.

\section{[[TABLE 4 ABOUT HERE]]}

\section{Perceived stigma}

In the first model, only gender and age were significant predictors for perceived stigma (see Table 5). Adding the interaction terms did not lead to a significant increase of $R^{2}$, although the increase approached significance, $p=.052$. In this second model, reframing was significantly associated with less perceived stigma for people without a personal history of mental illness. However, as indicated by significant interaction terms, two framing strategies increased perceived stigma for people with a personal history of mental illness: participants that had been exposed to either the frame $(M=3.93, S D=0.44)$ or the reframe conditions $(M$ $=3.72, S D=0.53)$ had higher perceived stigma compared to the control $(M=3.49, S D=$ $0.57)$.

\section{[[TABLE 5 ABOUT HERE]]}

\section{Internalized stigma}

The linear regression model regarding internalized stigma was significant, $R^{2}=0.31$, $F(9,60)=3.03, p=.005$, and revealed that there were only two significant predictors of internalized stigma, one's age and previous experiences of discrimination. People who are older have increased internalized stigma, $b=0.09$, 95\% CI $[0.02,0.16], \beta=0.31, p=.011$, as do people who have faced more discrimination in the past, $b=0.07,95 \% \mathrm{CI}[0.03,0.11], \beta=$ $0.73, p<.001$. None of the manipulations was able to significantly influence one's internalized stigma.

\section{Policy choice}

A large majority of participants $(78.86 \%)$ wanted that a history of mental illness would no longer be a criterion to decide whether or not to provide insurance. However, there 
were large differences between the experimental conditions, $\chi^{2}(3, N=400)=59.49, p<.001$. In the control group, $93.70 \%$ of participants opted for the criterion to be removed (i.e., the non-discriminatory option). This share was lower in all experimental conditions: frame $(52.77 \%)$, deframe $(86.78 \%)$, and reframe $(83.42 \%)$

A logistic regression analysis was conducted to gain further insight in the factors determining the policy choice (see Table 6). The model was statistically significant, $\chi^{2}(9, N=$ $400)=87.73, p<.001$, and correctly classified $81.50 \%$ of the cases.

\section{[[TABLE 6 ABOUT HERE]]}

When controlling for the other variables, participants who read the text using the stigmatizing frame were 14.98 times more likely than people in the control condition to choose to allow insurance companies to keep their current policy in place, compared to the control. Participants exposed to the text using the reframe, were 3.15 times more likely to opt to keep current policy. Participants exposed to the deframe condition were not significantly more likely than participants in the control condition to pick the discriminatory policy option.

\section{Discussion}

Using an online survey experiment, this study investigated the ability of framing, deframing, and reframing to reduce the stigma surrounding mental illness, both for people with and without a personal experience of mental health issues. The results indicated that framing strategies can indeed significantly reduce the stigma surrounding mental illnesses, especially public stigma.

The first research question asked which of the framing strategies suggested by Feagin (2010) would be most effective in reducing public stigma. Although Beukeboom et al. (2010) advised against using the negation of stereotypes in communication, the current results indicated that deframing is the preferable strategy: refuting the stigmatizing frame, using its language and arguments against it, significantly reduced public stigma of people without a 
personal history of mental illness, and did not significantly increase the likelihood that participants picked the discriminatory policy decision, compared to the control condition. However, deframing was not a significant predictor in the regression analysis for the semantic differential measuring perceived similarity, which was designed to be less prone to social desirability effects (Corrigan et al., 2015). This may indicate that the reduction of stigma was due to socially desirable responding: people may have simply become less willing to endorse stigmatizing statements, instead of their attitudes being altered. However, most other variables that were significant predictors in the regression model using the Likert-scale also lost their predictive power when predicting perceived similarity. While this does not exclude the possibility of social desirability bias, it could also indicate that perceived similarity with people with a mental illness is quite consistent across society and resistant to change.

Remarkably, exposing people without a personal history of mental illness to the stigmatizing frame lowered their public stigma. Likely, this is due to a backfire-effect (Chong \& Druckman, 2007a): because the stigmatizing frame was considered weak by most participants, it supported the opposite side of the argument and decreased stigma. However, because participants exposed to the stigmatizing frame had significantly higher odds to support keeping the discriminatory policy option in place, this seems to indicate that these participants still stigmatized people with a mental illness, and were only hesitant to endorse the stigmatizing statements present in the Likert-scale. Furthermore, even though most participants with a personal history of mental illness considered the stigmatizing frame to be weak, it significantly increased their public stigma. These participants may have felt compelled to set themselves apart from "people with a mental illness", who were described as abusing the system and having weak characters. Participants may have wanted to make clear that they also disapproved of such behavior. 
Based on the result of their meta-analysis, Griffiths et al. (2014) concluded that there is little empirical evidence regarding the reduction of perceived stigma and internalized stigma. As such, this study investigated how framing could reduce these kinds of stigma. For perceived stigma, only reframing was able to significantly reduce the perceived stigma of participants who did not have personal experience with mental illness, by drawing equivalences between the stigmatized group and the non-stigmatized group. However, for participants with a personal history of mental illness, reframing increased the perceptions of stigma, as did the stigmatizing frame. Whereas the increase associated with the exposure to stigmatizing frame was to be expected, it is harder to explain why the reframe increased perceived stigma for people with a mental illness. Perhaps it offered an overly optimistic representation, making the stigmatized group all the more aware that this does not correspond to reality, where they often face stigmatization. In response, they may have felt the need to stress that many people in society still hold stigmatizing attitudes towards them. However, this possibility could not be tested due to a lack of qualitative data.

To answer the second research question, none of the framed texts was able to decrease internalized stigma of mental illness. Other authors have noted the difficulty in combating internalized stigma: Stuenkel and Wong (2009), for example, have argued that "these internalized perceptions may be more difficult to deal with than the illness or disability itself" (p. 64). When frames contradict one's prior beliefs and attitudes, they are unlikely to be able to change one's opinion (Chong \& Druckman, 2007a). If one has internalized the stigma and truly believes it to be accurate, one brief message that counters these beliefs is unlikely to induce significant change. Moreover, it should be noted that none of the experimental stimuli in this study was able to significantly lower any kind of stigma for people with a mental illness. This suggests that framing is ineffective in reducing the stigma in people with a mental illness. 


\section{Limitations and further research}

This study investigated how framing could influence participants' stigma regarding mental illness, looking at both people with and without a mental illness. However, since only 70 participants in sample had personal experience with being mentally ill, the results for this group should be interpreted with care. Future research on reducing self-stigma using media content should specifically target their recruitment efforts to people with a mental illness, in order to gain sufficient statistical power.

The framed stimuli used ecologically valid frames for the Belgian context, but had some limitations as well. The goal of the study was to compare reframing and deframing as strategies to decrease framing, and as such, over $50 \%$ of the text is shared between these conditions. However, this text could not be adapted to be supportive of a stigmatizing narrative. As such, the text in the frame-condition differed from the other stimuli. Future research should take care to ensure that the stimuli are as comparable as possible, so that it becomes clear which specific attributes (e.g., arguments or word choice) lead to the framing effects on stigma.

To determine the validity of the results, the experiment should be replicated, using different frames that are pertinent to the topic and the setting of the study. Preferably, researchers should use frames from previous inductive framing analyses, to ensure the ecological validity of the frames.

\section{Conclusion}

This article demonstrated that the media can also help to combat stigma. By refuting stigmatizing statements, even a brief text is able to significantly reduce public stigma of people without a personal history of mental illness. The results also supported the existence of backfire-effects: if a stigmatizing frame was deemed unpersuasive, public stigma decreased. Similarly, unpersuasive destigmatizing frames were associated with higher public 
stigma. As such, pre-testing of anti-stigma messages is necessary, to ensure that they considered to be believable by all target audiences.

While reframing reduced perceived stigma for people without a personal history of mental illness, it increased perceived stigma for people with personal experience. As such, it is not an ideal strategy. Unfortunately, none of the strategies significantly reduced internalized stigma. These findings clearly indicate the importance to investigate how antistigma messages affect those who suffer from the stigma, before they are disseminated. 


\section{References}

Benford, R. D., \& Snow, D. A. (2000). Framing processes and social movements: An overview and assessment. Annual review of sociology, 26, 611-639. https://doi.org/10.1146/annurev.soc.26.1.611

Beukeboom, C. J., Finkenauer, C., \& Wigboldus, D. H. (2010). The negation bias: when negations signal stereotypic expectancies. Journal of personality and social psychology, 99(6), 978-992. https://doi.org/10.1037/a0020861

Brambor, T., Clark, W. R., \& Golder, M. (2005). Understanding interaction models: Improving empirical analyses. Political analysis, 14(1), 63-82. https://doi.org/10.1093/pan/mpi014

Bos, A. E., Pryor, J. B., Reeder, G. D., \& Stutterheim, S. E. (2013). Stigma: Advances in theory and research. Basic and Applied Social Psychology, 35(1), 1-9. https://doi.org/10.1080/01973533.2012.746147

Boyd, J. E., Otilingam, P. G., \& DeForge, B. R. (2014). Brief version of the Internalized Stigma of Mental Illness (ISMI) scale: Psychometric properties and relationship to depression, self esteem, recovery orientation, empowerment, and perceived devaluation and discrimination. Psychiatric rehabilitation journal, 37(1), 17-23. http://dx.doi.org/10.1037/prj0000035

Boysen, G. A., \& Vogel, D. L. (2007). Education and mental health stigma: The effects of attribution, biased assimilation, and attitude polarization. Journal of Social and Clinical Psychology, 27(5), 447-470. https://doi.org/10.1521/jscp.2008.27.5.447

Chong, D., \& Druckman, J. N. (2007a). A theory of framing and opinion formation in competitive elite environments. Journal of Communication, 57(1), 99-118. https://doi.org/10.1111/j.1460-2466.2006.00331.x 
Chong, D., \& Druckman, J. N. (2007). Framing theory. Annual Review of Political Science, 10, 103-126. https://doi.org/10.1146/annurev.polisci.10.072805.103054

Chong, D., \& Druckman, J. N. (2013). Counterframing effects. The Journal of Politics, 75(01), 1-16. https://doi.org/10.1017/S0022381612000837

Clair, M., Daniel, C., \& Lamont, M. (2016). Destigmatization and health: cultural constructions and the long-term reduction of stigma. Social Science \& Medicine, 165, 223-232. https://doi.org/10.1016/j.socscimed.2016.03.021

Corrigan, P. W., Bink, A. B., Fokuo, J. K., \& Schmidt, A. (2015). The public stigma of mental illness means a difference between you and me. Psychiatry Research, 226(1), 186-191. https://doi.org/10.1016/j.psychres.2014.12.047

Corrigan, P., Markowitz, F. E., Watson, A., Rowan, D., \& Kubiak, M. A. (2003). An attribution model of public discrimination towards persons with mental illness. Journal of health and Social Behavior, 44(2), 162-179. https://doi.org/10.2307/1519806

Crisp, A. H., Gelder, M. G., Rix, S., Meltzer, H. I., \& Rowlands, O. J. (2000). Stigmatisation of people with mental illnesses. The British Journal of Psychiatry, 177(1), 4-7. https://doi.org/10.1192/bjp.177.1.4

Druckman, J. N. (2001). On the limits of framing effects: who can frame?. Journal of Politics, 63(4), 1041-1066. https://doi.org/10.1111/0022-3816.00100

Druckman, J. N., \& Bolsen, T. (2011). Framing, motivated reasoning, and opinions about emergent technologies. Journal of Communication, 61(4), 659-688. https://doi.org/10.1111/j.1460-2466.2011.01562.x

Entman, R. M. (2010). Media framing biases and political power: Explaining slant in news of Campaign 2008. Journalism, 11(4), 389-408. https://doi.org/10.1177/1464884910367587 
Feagin, J. R. (2010). The white racial frame: Centuries of racial framing and counterframing. New York, NY: Routledge.

Griffiths, K. M., Carron-Arthur, B., Parsons, A., \& Reid, R. (2014). Effectiveness of programs for reducing the stigma associated with mental disorders. A meta-analysis of randomized controlled trials. World Psychiatry, 13(2), 161-175. https://doi.org/10.1002/wps.20129

Griffiths, K. M., Christensen, H., Jorm, A. F., Evans, K., \& Groves, C. (2004). Effect of webbased depression literacy and cognitive-behavioural therapy interventions on stigmatising attitudes to depression. The British Journal of Psychiatry, 185(4), 342349. https://doi.org/10.1192/bjp.185.4.342

Lecheler, S., Keer, M., Schuck, A. R., \& Hänggli, R. (2015). The effects of repetitive news framing on political opinions over time. Communication Monographs, 82(3), 339-358. https://doi.org/10.1080/03637751.2014.994646

Link, B. G., \& Phelan, J. C. (2001). Conceptualizing stigma. Annual review of Sociology, 27, 363-385. https://doi.org/10.1146/annurev.soc.27.1.363

Link, B. G., Struening, E. L., Rahav, M., Phelan, J. C., \& Nuttbrock, L. (1997). On stigma and its consequences: evidence from a longitudinal study of men with dual diagnoses of mental illness and substance abuse. Journal of Health and Social Behavior, 38(2), 177-190. https://doi.org/10.2307/2955424

Livingston, J. D., \& Boyd, J. E. (2010). Correlates and consequences of internalized stigma for people living with mental illness: A systematic review and meta-analysis. Social science \& medicine, 71(12), 2150-2161. https://doi.org/10.1016/j.socscimed.2010.09.030 
Major, B., \& O'Brien, L. T. (2005). The social psychology of stigma. Annu. Rev. Psychol., 56, 393-421. https://doi.org/10.1146/annurev.psych.56.091103.070137

Nawková, L., Nawka, A., Adámková, T., Rukavina, T. V., Holcnerová, P., Kuzman, M. R., ... \& Miovský, M. (2012). The picture of mental health/illness in the printed media in three central European countries. Journal of health communication, 17(1), 22-40. https://doi.org/10.1080/10810730.2011.571341

Reavley, N. J., \& Jorm, A. F. (2011). Stigmatizing attitudes towards people with mental disorders: findings from an Australian National Survey of Mental Health Literacy and Stigma. Australian and New Zealand Journal of Psychiatry, 45(12), 1086-1093. https://doi.org/10.3109/00048674.2011.621061

Rhydderch, D., Krooupa, A. M., Shefer, G., Goulden, R., Williams, P., Thornicroft, A., ... \& Henderson, C. (2016). Changes in newspaper coverage of mental illness from 2008 to 2014 in England. Acta psychiatrica Scandinavica, 134(S446), 45-52. https://doi.org/10.1111/acps.12606

Riles, J. M., Sangalang, A., Hurley, R. J., \& Tewksbury, D. (2015). Framing Cancer for Online News: Implications for Popular Perceptions of Cancer. Journal of Communication, 65(6), 1018-1040. https://doi.org/10.1111/jcom.12183

Schomerus, G., \& Angermeyer, M. C. (2008). Special articles stigma and its impact on helpseeking for mental disorders: what do we know. Epidemiol Psichiatr Soc, 17(1), 3137. https://doi.org/10.1017/S1121189X00002669

Stuenkel, D.L., \& Wong, V.K. (2009). Stigma. In P.D. Larsen \& I.M. Lubkin (Eds.), Chronic Illness: Impact and Intervention. (pp. 47-74). Boston, MA: Jones and Bartlett.

Van Gorp, B. (2007). The constructionist approach to framing: Bringing culture back in. Journal of communication, 57(1), 60-78. https://doi.org/10.1111/j.00219916.2007.00329.x 
Van Gorp, B., Vyncke, B., Vergauwen, J., Smits, T., Vercruysse, T., \& Vroonen, E. (2017). Een inspirerende kijk op de beeldvorming over personen met psychische problemen [An inspiring look at the representations of people with mental problems]. Brussels, Belgium: Koning Boudewijnstichting.

Whitley, R., \& Wang, J. (2017). Television coverage of mental illness in Canada: 2013-2015. Social psychiatry and psychiatric epidemiology, 52(2), 241-244. https://doi.org/10.1007/s00127-016-1330-4

Wise, D., \& Brewer, P. R. (2010). Competing frames for a public health issue and their effects on public opinion. Mass Communication and Society, 13(4), 435-457. https://doi.org/10.1080/15205430903296077 


\section{Tables}

Table 1 - Descriptive statistics

\begin{tabular}{|c|c|c|c|c|c|c|}
\hline Group & $N$ & Percentage & Variable & $N$ & $\begin{array}{c}\text { Possible } \\
\text { values }\end{array}$ & $M(S D)$ \\
\hline Gender & & & Stigma measures & & & \\
\hline Male & 200 & $50.08 \%$ & Public stigma & 400 & $1-5$ & $2.37(0.52)$ \\
\hline Female & 200 & $49.92 \%$ & Perceived stigma & 400 & $1-5$ & $3.58(0.51)$ \\
\hline Age bracket & & & Perceived similarity & 400 & $1-9$ & $5.36(2.21)$ \\
\hline $18-27$ & 67 & $16.77 \%$ & Self-stigma & 70 & $1-4$ & $2.01(0.43)$ \\
\hline $28-37$ & 52 & $12.92 \%$ & Other variables & & & \\
\hline $38-47$ & 38 & $9.46 \%$ & Previous contact & 400 & $0-7$ & $2.44(1.57)$ \\
\hline $48-57$ & 108 & $26.93 \%$ & Responsibility beliefs & 400 & $1-9$ & $3.07(1.24)$ \\
\hline $58-67$ & 38 & $9.38 \%$ & Experiences with & 70 & $0-11$ & $2.74(2.70)$ \\
\hline $68-77$ & 72 & $18.10 \%$ & discrimination & & & \\
\hline $78+$ & 26 & $6.45 \%$ & & & & \\
\hline \multicolumn{7}{|c|}{ Socio-economic status } \\
\hline Higher half & 211 & $52.70 \%$ & & & & \\
\hline Lower half & 189 & $47.30 \%$ & & & & \\
\hline \multicolumn{7}{|c|}{ Personal history with mental } \\
\hline Illness & & & & & & \\
\hline Yes & 70 & $17.54 \%$ & & & & \\
\hline No & 330 & $82.46 \%$ & & & & \\
\hline
\end{tabular}

Table 2 - Hierarchical regression analysis for public stigma $(N=400)$

\begin{tabular}{|c|c|c|c|c|c|c|c|c|}
\hline Predictor & b & $95 \%$ CI & $\boldsymbol{\beta}$ & $p$ & $\boldsymbol{b}$ & $95 \% \mathrm{CI}$ & $\beta$ & $p$ \\
\hline Constant & 1.99 & {$[1.75,2.23]$} & & **** & 2.01 & {$[1.77,2.25]$} & & **** \\
\hline Gender & 0.06 & {$[-0.03,0.15]$} & 0.06 & & 0.07 & {$[-0.02,0.16]$} & 0.07 & \\
\hline Age & 0.03 & {$[0.00,0.05]$} & 0.10 & $*$ & 0.03 & {$[0.01,0.06]$} & 0.11 & * \\
\hline SES & -0.14 & {$[-0.23,-0.05]$} & -0.14 & $* *$ & -0.15 & {$[-0.24,-0.06]$} & -0.14 & $* *$ \\
\hline Previous contact & -0.04 & {$[-0.07,-0.01]$} & -0.11 & $*$ & -0.04 & {$[-0.07,-0.01]$} & -0.13 & $* *$ \\
\hline Personal experience & -0.14 & {$[-0.27,-0.02]$} & -0.11 & $*$ & -0.32 & {$[-0.58,-0.06]$} & -0.24 & $*$ \\
\hline Responsibility beliefs & 0.15 & {$[0.12,0.19]$} & 0.37 & $* * *$ & 0.15 & {$[0.12,0.19]$} & 0.37 & $* * *$ \\
\hline \multicolumn{9}{|l|}{ Framing strategies } \\
\hline Frame & -0.11 & {$[-0.23,0.02]$} & -0.09 & & -0.20 & {$[-0.34,-0.07]$} & -0.17 & $* *$ \\
\hline Deframe & -0.14 & {$[-0.27,-0.01]$} & -0.12 & $*$ & -0.14 & {$[-0.28,-0.01]$} & -0.12 & * \\
\hline Reframe & -0.13 & {$[-0.26,0.00]$} & -0.11 & $*$ & -0.13 & {$[-0.27,0.01]$} & -0.11 & \\
\hline \multicolumn{9}{|l|}{ Interaction terms } \\
\hline Frame $x$ Experience & & & & & 0.61 & {$[0.26,0.95]$} & 0.25 & *** \\
\hline Deframe $\mathrm{x}$ Experience & & & & & -0.03 & {$[-0.41,0.35]$} & -0.01 & \\
\hline Reframe x Experience & & & & & 0.09 & {$[-0.23,0.41]$} & 0.05 & \\
\hline Model summary & \multicolumn{4}{|c|}{$R^{2}=.25, F(9,390)=14.66, p<.001$} & \multicolumn{4}{|c|}{$R^{2}=.29, F(12,387)=12.99, p<.001$} \\
\hline Adj. $R^{2}$ & \multicolumn{4}{|c|}{.24} & \multicolumn{4}{|c|}{.27} \\
\hline$R^{2}$ change & \multicolumn{4}{|l|}{$.25 * * *$} & \multicolumn{4}{|l|}{$.03 * * *$} \\
\hline
\end{tabular}

Note. $\mathrm{CI}=$ Confidence Interval

$* p<.05 ; * * p<.01 ; * * * p<.001$ 
Table 3 - Comparisons of stigma scores, depending on perceived persuasive strength $(N$ $=400)$

\begin{tabular}{lcccccc}
\hline & \multicolumn{7}{l}{ Low persuasiveness } & \multicolumn{2}{l}{ High persuasiveness } & \multicolumn{1}{c}{} \\
\cline { 2 - 5 } Condition & $\boldsymbol{N}$ & $\boldsymbol{M}(\boldsymbol{S D})$ & $\boldsymbol{N}$ & $\boldsymbol{M}(\boldsymbol{S D})$ & $\boldsymbol{t}$ & $\boldsymbol{p}$ \\
\hline Frame & 72 & $2.28(0.47)$ & 30 & $2.62(0.47)$ & -3.37 & $* *$ \\
Deframe & 25 & $2.62(0.54)$ & 75 & $2.24(0.46)$ & 3.37 & $* *$ \\
Reframe & 37 & $2.50(0.60)$ & 65 & $2.18(0.41)$ & 3.12 & $* *$ \\
\hline
\end{tabular}

Note. Lower scores indicate lower public stigma.

$* p<.05 ; * * p<.01 ; * * * p<.001$

Table 4 - Hierarchical regression analysis for perceived similarity with people with a mental illness $(N=400)$

\begin{tabular}{|c|c|c|c|c|c|c|c|c|}
\hline Predictor & $b$ & $95 \% \mathrm{CI}$ & $\beta$ & $p$ & $\boldsymbol{b}$ & $95 \% \mathrm{CI}$ & $\boldsymbol{\beta}$ & $p$ \\
\hline Constant & 6.23 & {$[5.09,7.37]$} & & $* * *$ & 6.25 & {$[5.10,7.40]$} & & **** \\
\hline Gender & 0.11 & {$[-0.32,0.54]$} & 0.02 & & 0.06 & {$[-0.36,0.49]$} & 0.01 & \\
\hline Age & -0.08 & {$[-0.20,0.04]$} & -0.07 & & -0.09 & {$[-0.21,0.03]$} & -0.08 & \\
\hline SES & -0.07 & {$[-0.52,0.38]$} & -0.02 & & -0.02 & {$[-0.46,0.42]$} & 0.00 & \\
\hline Previous contact & 0.06 & {$[-0.09,0.21]$} & 0.04 & & 0.07 & {$[-0.08,0.22]$} & 0.05 & \\
\hline Personal experience & 0.89 & {$[0.28,1.49]$} & 0.15 & $* *$ & 1.23 & {$[0.00,2.46]$} & 0.21 & \\
\hline Responsibility beliefs & -0.31 & {$[-0.48,-0.14]$} & -0.17 & $* * *$ & -0.31 & {$[-0.48,-0.13]$} & -0.17 & $* * *$ \\
\hline \multicolumn{9}{|l|}{ Framing strategies } \\
\hline Frame & -0.44 & {$[-1.04,0.17]$} & -0.09 & & -0.14 & {$[-0.79,0.51]$} & -0.03 & \\
\hline Deframe & 0.00 & {$[-0.61,0.61]$} & 0.00 & & -0.13 & {$[-0.78,0.51]$} & -0.03 & \\
\hline Reframe & 0.25 & {$[-0.36,0.86]$} & 0.05 & & 0.26 & {$[-0.41,0.93]$} & 0.05 & \\
\hline \multicolumn{9}{|l|}{ Interaction terms } \\
\hline Frame x Experience & & & & & -1.82 & {$[-3.47,-0.17]$} & -0.17 & $*$ \\
\hline Deframe x Experience & & & & & 1.20 & {$[-0.61,3.02]$} & 0.09 & \\
\hline Reframe $x$ Experience & & & & & -0.27 & {$[-1.81,1.27]$} & -0.03 & \\
\hline Model summary & \multicolumn{4}{|c|}{$R^{2}=.09, F(9,390)=4.19, p<.001$} & \multicolumn{4}{|c|}{$R^{2}=.12, F(12,387)=4.29, p<.001$} \\
\hline Adj. $R^{2}$ & \multicolumn{4}{|l|}{.07} & \multicolumn{4}{|l|}{.09} \\
\hline$R^{2}$ change & \multicolumn{4}{|l|}{$.09 * * *$} & \multicolumn{4}{|l|}{$.03 * *$} \\
\hline
\end{tabular}

Note. $\mathrm{CI}=$ Confidence Interval

$* p<.05 ; * * p<.01 ; * * * p<.001$ 
Table 5 - Hierarchical regression analysis for perceived stigma $(N=400)$

\begin{tabular}{|c|c|c|c|c|c|c|c|c|}
\hline Predictor & $b$ & $95 \% \mathrm{CI}$ & $\boldsymbol{\beta}$ & $p$ & $b$ & $95 \% \mathrm{CI}$ & $\boldsymbol{\beta}$ & $p$ \\
\hline Constant & 4.01 & {$[3.75,4.27]$} & & $* * *$ & 4.06 & {$[3.79,4.32]$} & & **** \\
\hline Gender & -0.12 & {$[-0.22,-0.02]$} & -0.12 & * & -0.11 & {$[-0.21,-0.02]$} & -0.11 & * \\
\hline Age & -0.05 & {$[-0.08,-0.03]$} & -0.20 & $* * *$ & -0.05 & {$[-0.08,-0.02]$} & -0.19 & $* * *$ \\
\hline SES & 0.00 & {$[-0.10,0.10]$} & 0.00 & & -0.01 & {$[-0.11,0.10]$} & -0.01 & \\
\hline Previous contact & 0.02 & {$[-0.01,0.06]$} & 0.07 & & 0.02 & {$[-0.02,0.05]$} & 0.05 & \\
\hline Personal experience & 0.08 & {$[-0.05,0.22]$} & 0.06 & & -0.20 & {$[-0.48,0.09]$} & -0.15 & \\
\hline Responsibility beliefs & -0.02 & {$[-0.06,0.02]$} & -0.06 & & -0.03 & {$[-0.07,0.01]$} & -0.07 & \\
\hline \multicolumn{9}{|l|}{ Framing strategies } \\
\hline Frame & -0.04 & {$[-0.18,0.10]$} & -0.04 & & -0.11 & {$[-0.26,0.04]$} & -0.10 & \\
\hline Deframe & -0.04 & {$[-0.18,0.10]$} & -0.04 & & -0.07 & {$[-0.21,0.08]$} & -0.06 & \\
\hline Reframe & -0.10 & {$[-0.24,0.04]$} & -0.09 & & -0.16 & {$[-0.32,-0.01]$} & -0.14 & $*$ \\
\hline \multicolumn{9}{|l|}{ Interaction terms } \\
\hline Frame x Experience & & & & & 0.47 & {$[0.09,0.85]$} & 0.19 & $*$ \\
\hline Deframe x Experience & & & & & 0.14 & {$[-0.28,0.56]$} & 0.05 & \\
\hline Reframe x Experience & & & & & 0.39 & {$[0.03,0.74]$} & 0.19 & $*$ \\
\hline Model summary & \multicolumn{4}{|c|}{$R^{2}=.09, F(9,390)=4.13, p<.001$} & \multicolumn{4}{|c|}{$R^{2}=.11, F(12,387)=3.79, p<.001$} \\
\hline Adj. $R^{2}$ & \multicolumn{4}{|c|}{.07} & \multicolumn{4}{|c|}{.08} \\
\hline$R^{2}$ change & \multicolumn{4}{|l|}{$.09 * * *$} & \multicolumn{4}{|l|}{.02} \\
\hline
\end{tabular}

Note. $\mathrm{CI}=$ Confidence Interval

$* p<.05 ; * * p<.01 ; * * * p<.001$

Table 6 - Logistic regression on policy choice $(N=400)$

\begin{tabular}{lcccl} 
Predictor & $\boldsymbol{b}$ & $\begin{array}{c}\text { Odds } \\
\text { ratio }\end{array}$ & $\mathbf{9 5 \%} \mathbf{C I}$ & $\boldsymbol{p}$ \\
\hline Constant & -5.17 & 0.01 & & $* * *$ \\
Gender & 0.81 & 2.25 & {$[1.27,4.00]$} & $* *$ \\
Age & 0.05 & 1.05 & {$[0.90,1.23]$} & \\
SES & -0.04 & 0.96 & {$[0.54,1.74]$} & \\
Previous contact & 0.21 & 1.23 & {$[1.01,1.51]$} & $*$ \\
Personal experience & -1.08 & 0.34 & {$[0.14,0.83]$} & $*$ \\
Responsibility beliefs & 0.45 & 1.57 & {$[1.25,1.97]$} & $* * *$ \\
Framing strategies & & & & \\
Frame & 2.71 & 14.98 & {$[5.78,38.83]$} & $* * *$ \\
Deframe & 0.73 & 2.07 & {$[0.73,5.85]$} & \\
Reframe & 1.15 & 3.15 & {$[1.14,8.66]$} & $*$ \\
\hline
\end{tabular}

Note. Cox \& Snell $R^{2}=.20 ;$ Nagelkerke $R^{2}=.31$

$* p<.05 ; * * p<.01 ; * * * p<.001$ 


\section{Appendix - Experimental stimuli (translated from Dutch)}

\section{Constant introduction}

Sometimes insurance brokers refuse to insure people with a mental illness. This happens in Belgium as well. This issue received media attention in Belgium in late 2015, because Belfius, a bank owned by the state, had rejected the insurance application of a young woman due to her history of mental illness. This happened even though her psychiatrist had declared she was cured. Critics thought that Belfius' decision was peculiar, especially because the bank is one of the main sponsors of the Rodeneuzendag, a campaign that aims to reduce the taboo on discussing mental illnesses.

\section{Frame}

\section{"More expensive insurance makes economic sense"}

Frederik De Troch, a health economist, argues that policyholders will be negatively affected if insurance companies are forbidden from using mental illness as a criterion.

It is a shame that insurance companies are criticized for this practice, while they just follow the economic logic. Obviously insurance brokers regret that they sometimes have to refuse clients, but the rules are the same for everyone. In order to keep the policies affordable, they always map the future risks of a client, based on the person's past, among other things.

Mental illnesses pose two important problems. First, they are difficult to assess objectively. This heightens the risk of abuse. One can never be completely sure if a person has actually been "cured". People with a mental illness can easily fake getting better to get a lower premium. This way, they make others pay for the costs of their psychological treatment. To protect their clients from this kind of abuse, insurance companies have to take the 
possibility into account that people paint an overly optimistic picture of their recovery process. That is the first reason for the higher premiums.

Secondly, a mental illness is often a sign that one is less able to cope with adversity. Even when they are said to have recovered, those people are more prone to addiction and suicide, among other things. A mental illness is an indication for higher risks, and higher risks are associated with higher premiums.

Moreover, insurance companies take into account that people with a mental illness often cannot continue to pay their premium, because they drop out of their job more often. To prevent further harm, the insurance is often denied.

If insurance companies can no longer take mental illness into account and are obliged to ensure them too, the premiums will irreversibly become a lot more expensive - for all clients. That is obviously something that needs to be avoided.

\section{Deframe}

\section{"Discriminating 24\% of Belgians"}

Frederik De Troch, a health economist, argues that it is unjust that a large group of people cannot obtain insurance due to their mental illness.

Let me begin by giving a number: an estimated $25 \%$ of Belgians will get a mental illness during their lives.

One in four. That is a remarkably high number.

People with a mental illness are often confronted with discrimination, including when taking out insurance. Whether it concerns hospitalization insurance, travel insurance, or guaranteed income insurance: when one has a mental illness, it is almost impossible to get insured at all, or the premium skyrockets. 
Because they are afraid of fraud, insurance companies have taken draconian measures that target a whole quarter of the population. 2.8 million Belgians are depicted as unemployed losers and even as abusers of the system, that should not get insurance - 'just to be sure'. That obviously is not an accurate representation of reality. Most people with a mental illness are regular, hard-working members of society. They have the right to be insured, but get blatantly discriminated, based on nonsense.

By now, we know that everyone can get a mental illness, from the regular man, woman, and child, to eloquent state leaders, top athletes, and successful businesspeople. Getting a mental illness has nothing at all to do with one's personality or lack of willpower. Even the best among us could be faced with a mental illness.

People with a mental illness are certainly not written off. A large majority of them works. A large majority of them recovers. It is wrong to assume that they have a permanent higher risk to get addicted or to commit suicide.

Why do people keep believing such fairy tales? It is high time that insurance companies stop this injustice. If they do not do take the initiative, the legislator should force them to.

\section{Reframe}

\section{"Discriminating 24\% of Belgians"}

Frederik De Troch, a health economist, argues that it is unjust that a large group of people cannot obtain insurance due to their mental illness.

Let me begin by giving a number: an estimated $25 \%$ of Belgians will get a mental illness during their lives.

One in four. That is a remarkably high number.

People with a mental illness are often confronted with discrimination, including when taking out insurance. Whether it concerns hospitalization insurance, travel insurance, or 
guaranteed income insurance: when one has a mental illness, it is almost impossible to get insured at all, or the premium skyrockets.

This is despite the fact that people with a mental illness are just regular people. Their mental illness is just one part of them. Even so, they are judged because of it. That is as if people would be denied insurance just because they are left-handed, or because they have a certain skin color. Those traits say nothing about the person as a whole, and the same applies to people with mental illnesses. One should always consider the person as a whole, instead of reducing them to one aspect.

By now, we know that everyone can get a mental illness, from the regular man, woman, and child, to eloquent state leaders, top athletes, and successful businesspeople. Moreover, we're all a little "crazy". If the insurance companies want to be completely consistent, they should not allow people who belief in God get insurance, nor people who are superstitious. After all, such "magical thinking" can also be seen as a symptom of obsessivecompulsive disorder.

For that reason, we should stop using labels and approach everyone as full individuals. It is high time that insurance companies stop this injustice. If they do not do take the initiative, the legislator should force them to. 